\title{
Environment, Ecology, Climate and 'Nature' in 21st Century Scottish Literature
}

\author{
Graeme Macdonald ${ }^{1, *}$ and Carla Sassi ${ }^{2, *}$ \\ 1 Department of English and Comparative Literary Studies, University of Warwick, Coventry, \\ Warwickshire CV4 7AL, UK \\ 2 Department of Foreign Languages and Literature, Verona University, 37129 Verona, Italy \\ * Correspondence: g.macdonald@warwick.ac.uk (G.M.); crlsassi@gmail.com (C.S.)
}

Citation: Macdonald, Graeme, and Carla Sassi. 2021. Environment,

Ecology, Climate and 'Nature' in 21st Century Scottish Literature.

Humanities 10: 34 .

https://doi.org/10.3390/h10010034

Received: 26 January 2021

Accepted: 5 February 2021

Published: 23 February 2021

Publisher's Note: MDPI stays neutral with regard to jurisdictional claims in published maps and institutional affiliations.

Copyright: (C) 2021 by the authors Licensee MDPI, Basel, Switzerland. This article is an open access article distributed under the terms and conditions of the Creative Commons Attribution (CC BY) license (https:// creativecommons.org/licenses/by/ $4.0 /)$.

\section{Introduction: The Morning after}

A pivotal scene in the 2019 reinvention of Bill Forsyth's 1983 film Local Hero into musical theatre ${ }^{1}$ involves a hangover. The cast collectively suffer the adverse effects of the previous night's raucous ceilidh, a celebration electrified by the drunken promissory of a community windfall. Knox Oil, a US oil company seeking to raze the sleepy Highland village of Ferness and its surrounding area for petro-development, has proposed a buyoff. The scene, which opens the second half, is a deliberate mood-killer. As it develops, it platforms the environmental reckoning at the core of the plot. A comically entitled song, "Never Felt Better" establishes a performative contrast between heady prospects and sharp sobriety, further conveyed by distinct dramaturgical transitions between tenor, movement, lighting, tone, volume and lyric. The film uses similar ironic contrasts to build its general atmosphere of whimsical hope, anticipated loss and wistful regret in the face of the social tumult and terraforming that oil would bring. This transformation, experienced unevenly by different constituencies in Scotland, is registered somewhat archetypally by the various characters in Local Hero, in their predicaments and in the dashing of their prospects. We need not be familiar with the original to recognise familiar contradictions.

A considerable weight of temporal irony freights Local Hero's 21st century guise. Forty years on, amidst a mounting climate crisis with its roots in the century-long intensification of fossil-fuelled civilisation, pressures surround the inevitable end of North Sea oil. They emanate from acute realisation of its negative consequences for both local ecologies and earth-scale environmental systems. The extent to which this haunts the conscience, actions and decisions of (most of) Forsyth's characters is a question a contemporary audience also confronts. Immediate interests are weighed against historic potential: to enable or prevent the continuation of a petromodern world with long-term, potentially irreversible effects; to incur a hangover to surpass all others-one without diminishment.

Forsyth's film was made and released in the wake of the tumultuous oil shock/petrodollar decade of the 1970s. New fields were being discovered in the North Sea despite the first identification of looming peaks. Considered afresh, from the range of perspectives now available in the expanded field of Environmental Humanities, Local Hero-like numerous other examples in the present and historical firmament of Scottish literature and culture-becomes irretrievably environmental, in more extensive, perhaps unexpected ways than originally understood. Viewed through the lenses of the recently instituted field of Petroculture, ${ }^{2}$ for example, this modern morality tale shares some affinity with the longer history of literary, theatrical and cinematic stories of extractivism. These often focus

1 Local Hero, directed by John Crowley, was officially premiered at the Lyceum, Edinburgh, 23 March 2019. The book was written by Bill Forsyth and David Greig, the music and lyrics by Mark Knopfler.

2 For key primers on Petroculture, see Barret and Worden (2014), LeMenager (2014), Szeman (2019), Wilson et al. (2017). The Petrocultures Research Group is @ https://www.petrocultures.com/ (accessed on 17 December 2020). See also https://www.energyhumanities.ca/ (accessed on 9 February 2021). 
on repeated rounds of accumulation by dispossession on the world's resource zones and peripheries and are, in turn, encased within the larger narrative rubrics of industrialisation's long reach through modernity. They are recast again in contemporary environmental criticism within the era and phenomenon of the Anthropocene.

There remains disagreement on whether to regard optimal Anthropocene dating in the mid-20th century as a later staging point of the wider and longer process of colonisation, industrialisation and anthropogenic impression on natural environments in modernity, what Moore (2016) has called the "Capitalocene". Anthropocene literary criticism has had to grapple with this point, which impacts on boundary and framing questions of periodisation and geography as much as it challenges interpretive work. Adam Trexler, for example, opens his Anthropocene Fictions (Trexler 2015, p. 1) echoing Crutzen and Stoermer's (2000) origin paper that considers James Watt's 18th century steam engine breakthroughs as a valid starting point. Many critical voices have regardless argued that the identification of this process (whatever and whenever we choose to call and date it) brings fundamental changes to the ways in which literary forms, genres and their histories can be read and understood as historical, geo-cultural or aesthetic registers of environmental and ecological phenomena. As we assert in this introductory essay, critics of Scottish literature are not spared such methodological and epistemological challenges, and we attempt in what follows to open out some general and pointed questions thrown up by them.

\section{Environmental Politics}

As our contributors were preparing their essays, Glasgow was chosen to host the major global UNFCCC event of COP26 $6^{3}$ (scheduled for 2020 but delayed to 2021). Understood as the most significant Conference of the Parties since COP21 in Paris in 2015, this has been seen in some quarters as some form of recognition of the reputation Scotland was gathering as an ambitious net zero actor. There has indeed been a strong vision, this century, of Scotland as a place of positive environmental action and intent. There exists solid evidence of multiple initiatives at community, civil and governmental level to support this view, though intent does not always translate to action. The Scottish Government has also been envisioned as a vanguard site of climate policy. ${ }^{4}$ The reality is more complex, not only due to some of the problems and contradictions that Dominic Hinde in the present collection ${ }^{5}$ and others point out, and for some elements comparable to the culture of corporate greenwashing, but also in the form of carbon hypocrisy generated by the continuing strong presence of the oil and gas industry in Scottish politics, economy and culture. ${ }^{6}$

The crucial global attention COP26 offers to Scotland affords opportunity for deeper reflection and scrutiny of its present and historical character as an environmental actor. The conference was scheduled to take place in the year following the James Watt

3 See https://www.ukcop26.org/ (accessed on 9 February 2021).

4 The limits and opportunities of devolved constitutional politics and governance require mentioning here, namely that the Scotland Acts of 1998 and 2016 reinforced most elements of energy policy as a reserved executive matter for Westminster. Notwithstanding the multi-national logistics and power of the fossil fuel industry across the United Kingdom, under these terms, Scotland cannot be fully "energy independent". Little (2016) notes the nuances and contradictions in these restrictions, which are exacerbated by the fact that environmental and climate policy is devolved. Aspects of planning are devolved, however, meaning renewable energy projects can be managed and other energy developments (such as onshore fracking) denied a license. The Scottish Parliament Climate Change Acts of 2009 and 2019 have allowed for and created a certain degree of divergence between Scotland and rUK policy. This has not prevented schemes and partnerships with other regions and places at "sub-national" level, especially around climate policy. See Bomberg and McEwen (2014).

5 "Something Super-Wicked This Way Comes: Genre, Emergency, Expectation, and Learning to Die in Climate-Change Scotland." https://www. mdpi.com/2076-0787/9/1/17 (accessed on 17 December 2020).

6 There is considerable literature on this issue. For a detailed overview of the contemporary contours surrounding the oil and gas industry in Scotland, as well as the alternatives advanced by transition initiatives, see Christopher Silver's $(2018-2019,2020)$ series of reports for DesmogUK. For a critical take on the "lack" of ambition in the Climate Plan, see the various reports by the campaign organisations FOE Scotland: https:/ / foe.scot/ (accessed on 17 December 2020) and Stop Climate Chaos Scotland: https:/ / www.stopclimatechaos.scot/ (accessed on 17 December 2020). In the wake of The Scottish Government's 2019 declaration of a Climate Emergency, the formidable challenge of meeting $\mathrm{CO}_{2}$ emissions reduction targets within the real terms for a just transition and effectively keeping to the Paris Agreement has been placed by Kevin Anderson (2020), in his address to the 2020 Scottish Climate Assembly, as at $10 \%$ per year for at least the next decade, approx. ten times more than present rates. 
bicentenary, which heralded exhibitions and events in Glasgow and around the country celebrating this famous Scot's life and achievements. ${ }^{7}$ It is noteworthy, then, that one of the most significant academic works of energy and environmental humanities to be published this century, Andreas Malm's Fossil Capital (2016), describes Watt's 1784 patent for his rotative steam engine as the "earth-shattering exploit" (p. 16) originating the modern fossil economy. Watt's 1765 eureka moment for steam power took place, of course, on Glasgow Green. This is viewed in Malm's compelling narrative as a kind of ground zero for where the world is at now, and the subtitle of his book-The Roots of Global Warming - cements this assertion. This stark reminder of Scots' and Scotland's key role in the historical formation of fossil-fuelled capitalism is further elaborated in other notable work. Naomi Klein (2019) book On Fire, for example, reminds us of the publication of Adam Smith's The Wealth of Nations in the year following Watt's initial breakthrough. Together with the US Declaration of Independence, and six years after Cook's "discovery" of Queensland in Australia, this period forms the nexus of a modern world-system forged by "colonialism, slavery, coal, capitalism" (pp. 195-96).

The critical Scottish contribution to fossil modernity is further consolidated in the 19th century by numerous other Scottish vanguard figures from across the disciplines, emphatically elaborated in Cara Daggett (2019) ground-breaking book, The Birth of Energy, where Scotland-and Glasgow in particular-is framed and sourced as a crucible for the modern world's scientific-engineering and philosophical-economic approach to energy (and, in particular, to thermodynamics). ${ }^{8}$ The understanding of energy as a cultural phenomenon as much as a matter of physics and engineering was vital to the social engine of moral and political economy in forming long-lasting ideas of growth, work, labour and imperial identity, consolidating and reproducing what has been called the "Thermocene" (Bonneuil and Fressoz 2016). It is a history being reassessed for its toxic heritage today.

These are sobering legacy questions for 21st century Scottish environmental humanities to extrapolate as it advances. But it should also be stressed that there are other, more positive heritages to consider. Malm's history also records the importance of early experiments with hydropower and water sanitation by the likes of Scottish civil engineer Robert Thom (1774-1847) in 19th Century Greenock as a breakthrough moment in environmental history that should be highlighted to encourage the means to realise a "return to the flow" (Malm 2016, p. 367). This extends into the 20th century through figures like Tom Johnston and his pioneering work to establish hydro power in the Highlands, dramatized in Robert Dawson Scott's play The Electrifying Mr Johnson, developed and toured by Comar/Mull Theatre in 2019. Cultural work provides a means to engage with such modern and feasible civic and infrastructural projects abandoned and displaced by the rise of steam and other energy sources. This can only help deepen a perception of renewable energy forms as a "history for the future", as the social and natural limits of non-renewable modes of energy and its society are increasingly exhausted and exposed. In fact, the critique and realisation of resource limits and the tendency towards exhaustion through mismanagement and excessive appropriation and overuse is, as scholars like Fredrik Albritton-Johnson (2013) and T. C. Smout (2000) have demonstrated, a persistent feature in the history of Scottish culture since the Enlightenment. There have been identifiable strains of "environmentalism" in operation since, through multiple sites, figures and organisations. ${ }^{9}$ We see the essays in this collection as operating in tandem and reconnection with that spirit and tradition. The

7 See https://www.jameswatt2019.org/ (accessed on 17 December 2020).

8 This is not to wholly denigrate some of these crucial and exceptional scientific and technical achievements, nor to fail to see the emancipatory and extraordinary qualities, refinements and attractions of fossil-fuel culture, through coal, oil and gas. Rather, it is to insist on an environmental and social reassessment of the dark ecologies and often corrupt politics that the fossil era and its expansive and wasteful cultures of speed, exploitation and limitless consumption have wrought.

9 Albritton-Johnson's book situates the material properties and intellectual discourse around the 18th century Highlands as at the forefront of modern environmental ideas. Debates about the physical limits of natural resources and their management, amid contested theories of economic growth, have proved remarkably resilient and have intensified in the age of concern for global heating. Scottish thinkers from Carlyle (see Jessop 2012) to Patrick Geddes (Studholme 2007) have been viewed as pioneering figures across the 19th and early 20th century for their evolution of a theory (and terminology) of environment which entangles (not always harmoniously) the natural with the cultural. 
important proviso is that they now work in an altogether different episteme, writing with detailed knowledge of the effects of the fossil fuel era and under the sign of accelerating climate change. In such a context Scotland-and Scottish culture too-might have to "own" its larger environmental culture in part as a kind of reckoning with what Watt, Thomson, Rankine, and others delivered to the world: the means of industrial fossil modernity and its ongoing hangover.

\section{Post/National Ecologies}

The present collection arises from a desire to encourage a larger and more consistent conversation about what Scottish literature does with "environmental humanities", how it locates and finds itself within or next to (or even outside) that multi-disciplinary field. In particular, it attempts to question and redefine the national as local and as globally enmeshed as a useful category of thought in that ever-expanding corpus and its larger enframing in environmental studies. Far from reclaiming conventional 18th-/19th-century ideas of nation and nature, the purpose of this angle of enquiry and critique is to explore the ways in which an "imagined community" may integrate (or indeed reject) particular ecological and cultural affiliations. The specific perspective of 21st century "Scotland" (both a territory - a system of bio-regions connected among them and beyond the borders that define Scotland and Britain-and a political aspiration of sovereignty in some form), along with an understanding of the important and sometimes radical debate on environmental issues that has developed here in the past two decades, may indeed foreground the notion of an in(ter)dependent (post)national ecology, but one also irrevocably connected to smaller and larger units and processes of ecological measurement and environmental phenomena.

We are interested in the way in which nation-oriented perspectives and projections are as compelling as they are limiting, and how this in itself might be generative for environmental/ecological action. There is more than one effective methodology and approach available. A recurring feature, for example, in several essays here is attention to a classic shibboleth of ecocriticism: the granular perspective; a mode of intense noticing garnered from close observations of the natural world. This has been a staple feature of what might be called "classical" nature writing and appears in many literary accounts of environmental awareness. What we do now with such registration is a nagging question. There is no doubt that the intense aesthetic appreciation of, say, a net-winged beetle, a morning haar, a basking shark or a raised beach can be rendered for and in itself, without any requisite eco-materialist framing. The extent, however, to which this practice can overly fetishise the microscopic view and disregard larger processes of cause and effect-and threat-is a developing matter for ecocritical debate.

One of the most significant Scottish writers of the 21st century, Kathleen Jamie, has made nature, ecology and environment a persistent focus in her work. In doing so, Jamie has explored and interrogated slippages and interconnections between settled categories of nature or wilderness and historical human action in and upon it. Both Louisa Gairn (2008), in her landmark 2008 volume, Ecology and Modern Scottish Literature, and Deborah Lilley (2013) draw particular attention to the essay "Markings", from the Findings collection, where Jamie (2005, p. 126) describes the "subtle marks" long made by humans and animals in and upon the natural environment. These she evocatively suggests as the striated lines and overlaps between human and extra-human nature at broader scales of time and space. There is more than a hint of affiliation here with Anthropocene discourse, and the stratigraphic phrasing resonates with the established ecocritical notion of finding and conceptualising the ecological in unexpected ways and places throughout history and geography. "Subtle marks" also evoke the process of writing and literary practice, of course, and, as Timothy Clark (2015) has argued, the interface between the realms of the literary and the Anthropocene present a formidable challenge for literary critics to think deeply about the nature, ambit and ultimately the efficacy of their practice in this context.

Clark emphasises the manner in which the Anthropocene phenomenon amplifies in part by the sheer power of its banality. In such a form it politicises, by manifesting 
itself in "innumerable possible hairline cracks in the familiar life-world, at the local and personal scale of each individual life". This resonates on some level with Jamie's concerns about an overly idealised sense of nature, especially notions of wilderness somehow untouched by the realms of the social. For Clark, "something planetary is breaking through, entailing a politicization of what may once have seemed insignificant, as familiar day-today practices incite an engaged 'green' political awareness" (Clark 2015, p. 9). The terms of this engagement-representative, generic, constitutive, affective, etc.-remain debatable. Nevertheless, finding connections between the apprehension and appreciation of nature in miniature and larger political, legal, and ethical frameworks that either protect or threaten the web of life is central to this view. And cultural forms and expressions are involved mechanisms in this process.

If a central aporia in the contemporary debate on global environmental issues can be identified in a trend for holding "state systems and boundaries" irrelevant as "means for understanding and addressing questions of nature," in reality, "nature is continually being ordered and framed by nation-states" all over the world (Whitehead et al. 2007, p. 1). The nation-state, by promoting processes of centralisation and territorialisation, has indeed "been central in orchestrating our modern conceptions of the natural world" (Whitehead et al. 2007, p. 21). National framings of nature and landscape have often been deployed by states in order to forge coherent visions of unity and legitimise territorial claims (Whitehead et al. 2007, pp. 8-12). A core tension here sits between the desire and need to transcend a political model that is perceived as intrinsically flawed and doomed to repeat the same patterns of domination and exploitation of the environment, and the difficulty, or indeed the impossibility, to relinquish a concept/terrain that is deeply ingrained in political discourse as much as it is in the disciplinary concerns of Scottish literature. A geographical or "nature"-oriented imagination of nations and regions has in fact been much more common than has been generally recognised by scholars of nationalism, who have focused their attention mostly on cultural or political aspects.

Iconic landscapes, symbolic natural elements, such as rivers and mountains, or animals often compound national identities in Europe and across the world. Many of such figurations have in fact a relatively recent origin, as they usually date back to the 19th and early 20th century, when the establishment of geography as an academic subject had a great impact on the consolidation of national imaginaries. By highlighting the correspondences between places, stories and identities, geographers fostered the use of "landscape figures" as emblematic objects of national and local identities (Walter 2004). The popularity of emblematic environmental figures, still symbolising the bond between humans and environment in national imaginaries across the world, may be seen as relatively innocuous expressions of "banal nationalism," unmarked details to which we are exposed on a daily basis and that subliminally shape our passive sense of national identity (Billig 2010, pp. 1-12). The "Scottish weather" might be such an example, though amidst a climatic phenomenon where present and future weather is viewed (sometimes mistakenly) as a primary marker of longer patterns of changing climate, all manner of abstract elemental properties and environmental figures become subject to national territorial and cultural conceptions. What is the "Scottish" air if subject to drifting wildfire smoke from another continent or subject to $\mathrm{CO}_{2}$ emissions in international airspace? Conversely, what, under the international rubrics of climate justice, is the territorial reach and atmospheric legacy of "Scottish oil" (or indeed, imported Texan fracked gas) if its latent effects are enacted in other vulnerable settings around the world palpably more susceptible to the cumulative pressures of global heating? What might the story of a Syrian refugee on a Scottish island tell us about the shifting borders, identifying contours and manifestations of climate change in Scotland and elsewhere?

It goes almost without saying that "natural" symbols may form the basis of aggressive forms of ethnonationalism, focused on blood-and-soil ideology, portraying territory as an ancestral right and identifying nature as a fixed and heritable norm against which exclusive notions of ethnic or racial identity are established. There are, it should be stressed, situations 
when "national nature" can be mobilised into extremist forms of eco-fascism. As Ursula Heise (2008, p. 9) has noted, for example, modern German environmentalism is haunted by the dark legacy of the Nazi appropriation of romantic ecology and its enthusiastic embrace of "green" practices and credentials.

While it is certainly correct to claim that "modern states, especially in Europe and North America, have construed their visibility and their legitimacy through landscapes emblematical of the territories on which they exercised their sovereignty," and that 'landscape' can thus be seen "as one of the numerous devices intended for the construction of a national territory and a corresponding national society, specifically through the manipulation of the appropriate symbology," (Debarbieux and Salzani 2011, p. 138), it would be wrong to believe that this type of imagination is inscribed, by default, in the very concept of nation. Nationalism is indeed often preoccupied with issues of autonomy and sovereignty, and it may even take the shape (as it has on occasion in Scotland) of what has been named "resource nationalism" - the intended exploitation of natural resources for the exclusive benefit of a nation-state, real, imputed or imagined. But nation and state, even though often conflated, do remain two distinct, potentially connected and potentially conflicting concepts, and environmental issues are increasingly central to the nature of the connection. The former focuses on the shared (and sometimes disputed) values and ideals of a community, the latter expresses an institutional translation of such values and ideals into a set of codified practices and rules. And while nation-states may realise, to a certain degree, a synthesis of the two terms, there are a number of contexts-a stateless nation, for example-where the two concepts may indeed remain quite independent of each other.

Scotland's 21st century political imaginary is often characterised by narrative claims to future sustainability, in policy and aspiration. A notable feature of 21st century devolved governance and arguments around sovereignty and independence, for example, has attempted a distinctive envisioning of Scotland as a clean energy leader. These project prominent claims towards a future state powered by renewable energy, producing powerful images of a renewed future polity. And yet, as Hinde points out in his article in the collection, this may also be identified as a classic narrative of "ecological modernisation" (p. 2). Here, aspirational narratives representing a clean utopian future roughly mappable with the cartographies of capitalist modernity as we know it neither meet the full and challenging realities of mitigating climate change head on nor promise a fully just transition. Can, then, the concepts of nation and state in the Scottish context be radically rethought, easily transcended or even usefully reclaimed in the discourse of Scottish environmentalism and climate change? If so, under which conditions? And what role-if any-has the literary to play?

If the term nation has come, especially in the aftermath of WW2, to most commonly stand in political and academic discourse for exclusive, closed and patriarchal constructions of collective identities, the truth is that it defies simple, univocal definitions. In the modern age, it has embraced very different and even conflicting attitudes and imaginaries from ethnocentric to civic practices, from totalitarian to democratic expressions, from imperialist expansion to resistance to imperialism. Arguably, in its most general meaning of an "imagined community" (Anderson 2006) characterised by a complex set of "beliefs, assumptions, habits, representations and practices" (Billig 2010, p. 6), the nation, as both an abstract concept and a social reality, is indeed fluid and open to transformation, even in an ecological/environmental direction. In this respect, it may be worthwhile to point out that among the obsolete extended meanings of the word nation, the Oxford English Dictionary lists "a particular class or kind of person" (citing the phrase man's nation signifying "mankind"), and "the animal kingdom, the world of animals," both in use between the 14th and 18th century (OED Third Edition, June 2003). Interestingly, then, it is within the very etymological layers that make the term that we may trace the basis for a possible ecological vision of the idea of national community-as not exclusive of other kinds of belonging, and stretching to embrace "mankind", but also pushing beyond any restrictive or exclusive definition of this term and including elements, atmospheres, 
pollutions zones, energy infrastructures, geologies, as well as new forms of extra-human relations, interspecies politics and bioregional affiliations.

The ecological possibilities inherent in the otherwise fluid term nation, largely unexplored by its theorists, have been nonetheless considered in 20th century literary texts. The influential American novel Ecotopia: The Notebooks and Reports of William Weston (1975) by Ernest Callenbach is probably the most famous example, describing the rise of a new, green nation, merging Northern California, Oregon and Washington, founded on a philosophy of shared ecological values and a focus on the equitable production of renewable energy. ${ }^{10}$ Ecotopian national imaginaries remain outweighed, however, by countless examples of eco-dystopian ecological regimes. Scottish fiction has provided notable examples, such as Alasdair Gray's Unthank in Lanark (1981) or George Mackay Brown's Greenvoe (1972) or the strange post-industrial world of John Burnside's Glister (2008). Eco-authoritarian states and communities appear in various modalities, meanwhile, in Michael Russell's The Lie of the Land (2015) and Burnside's more recent critical-utopian narrative, Havergey (2017), which Arianna Introna writes about in her essay in this collection.

21st century criticism (Wallerstein 2006; Lieven 2020; Hickel 2020) from right and left has argued that the environmental consequences of unevenness in the inter-state world system will increasingly determine the nation's form. Added pressure comes from the consolidating realpolitik that views the threats and transformations of climate change as a first-order issue of national security. Some form of national environmental imaginary cannot, therefore, be wished away, despite all manner of entanglements and intersections between different extra-national forms, geo-cultures and their cultural productions in globalisation. How distinct, for example, is Scottish cli-fi or ecopoetics or petroculture from, say, the North American variety? Do the imaginaries and textures of Scottish 'rewilding' resonate in European or other boreal and peatland contexts? The advent of the international climate talks has instituted a supra-national body of authority (IPCC), with trans-national networks of expertise, policy-making, creative activity and activism. These are often pitted against a general politics of nation-state actors principally motivated by the inward strategic realism of competing state interests. These are subject in turn to the expansionary impulses and networks (material and financial) and securitised trade corridors of capitalist globalisation. Does cultural work and its critical interpretation follow a similar formation?

Finally, we must here acknowledge writing this introduction amid a world pandemic. This is in itself a deeply world-ecological phenomenon revealing the public health and environmental consequences of the appropriative acts driving capitalism's seemingly limitless incursions in wilderness and animal habitat; its dramatic transformations of travel, health, diet and sense of range and place. Solutions to mitigate and eradicate a global virus issue familiar contradictory tendencies. In places they resemble those of emissions reduction or urban transition, where a fundamental requirement for unisonant actions (on, for example, vaccine research and development) confronts the predisposition of nation states entangled with trans-national corporate industries (such as healthcare or auto-manufacture) to seek to act in their own political and economic self-interest in the face of existential crisis.

\section{Re-Reading Scottish Literature Environmentally}

It will be interesting to see how Scottish literature and its various critical constituencies might confront, register, elaborate and reconstitute not only these immediate issues and concerns but also the range of others we have covered here and apparent across the environmental humanities. The variety of positions on 21st century Scottish texts gathered in this Humanities Special Issue might legitimately be applied as a means of (re)reading a

10 The undergirding notion here is that of the pioneering place that might spur other states or regions to adopt similar infrastructures and policies. In recent history, given the 'planetary' nature of climate change politics, alliances operate across and beyond nation-nation collaborations, such as 'soft' initiatives between the Scottish Government and California (Scottish Government 2017), or more frequently in transnational urban resilience policy sharing or in international organisations and activist networks, from FOE to Extinction Rebellion. 
work such as Local Hero (and indeed the historical constellation of texts gathered under the sign of Scottish writing) "environmentally": its concern for and appreciation of "natural" landscape; its intermittent focus on the animal or non-human other; its registration of the offshore and the marine environment (under the rubrics of the "energy" or "blue" humanities); its subplot exposing the correlations between the world of petrodollar finance, secretive forms of flexible accountancy and eco-accountability; its posing of the socialised relations of cheap or capitalised nature around land ownership and conservation, as a form of "world-ecology"; its ethical attentiveness to relations of care and future-oriented postcarbon modes of community and habitat. Its fundamental orientation, in its final rejection of petromodernity, amidst rumination on the cosmos, geological time and planetary system also offers a deep time perspective on how to scientifically understand and romantically wonder at (perhaps even overly sentimentalise) "nature" and humans operating in and on it. But this also opens out questions concerning how to comprehend the material and symbolic value of what we understand to be "environment" or "planet"; to realise the historical roots of "nature's" political and philosophical elaboration and the manner in which it is comprehended through geo-economic networks of power, environmental politics and cultural expressions thereof. It goes without saying that such a work as Local Hero comes with "readymade" identifiable "ecocritical" issues and perspectives for the 21 st century critic to realise and refurbish. An equally important question for future critics to grapple with is how to recognise the environmental aspects of ostensibly nonenvironmental Scottish texts within that Anthropocene context we explore above? The essays in this collection open out many of the perspectives listed and offer new means and methods to comprehend the ecocritical and environmental range of Scottish literary texts.

Dominic Hinde's "Something Super-Wicked This Way Comes: Genre, Emergency, Expectation, and Learning to Die in Climate-Change Scotland" assesses the various climatefacing narratives in Scotland surrounding the promise and condition of future sustainability. The provocation that he makes identifies shortcomings in a range of policy, industry and media positions. These are based on what Hinde theorises as the "normalising" effect that these narratives of ecological modernisation have-even those deemed "leading" and "ambitious"-in persuading publics that adequate solutions to what is coming (and indeed that which has already cumulatively taken place) will likely be met. This has constructed a mode of "climate realism" in Scotland, which is anything but realistic, amounting to a "failure to recognize the long-term negative impacts on those its promotion ostensibly seeks to help" (p. 6). This Hinde sees as a kind of "genre trap" (p. 2). He argues that this is where the counterfactuals and alternative narrative imaginings, even the "irrealisms" that literature produces, find a way to intercede and transgress upon normalising narratives that cannot or will not confront the coming problem in the way that its radical changes demand.

Rebecca Ford's article "Orkney Ecologies" theorises Orcadian society as a kind of social-ecological meshwork, via an assemblage of her own community fieldwork-the material and aesthetic impressions of the island's literary heritage and the emergent culture of renewables. Leaning on the work of Maria Puig de la Bellacasa (2017), Ford argues that an ethos of care is central to the island's efforts to orient itself to environmental transformation. Claims to renewability and ideas of resilience are not, however, without considerable problematics and precarity. Her ecocritical approach to Amy Liptrot's The Outrun (2015) sees the conjoining of a renewed psychological state with an Orcadian context of renewable energy "at the edge of the world", to paraphrase the title of Laura Watts' 2019 book. Along the lines of Watts' ethnographic and poetic description of Orkney's emergence as an international avant-garde space for renewable technology development, Ford poses the Orcadian space as a place that might potentially offer a different way forward than the just-in-time world of the megacity or suburban consumer culture reliant on carbon.

In "Nuclear Deficit: Why Nuclear Weapons Are Natural, but Scotland Doesn't Need Nature", Michael Gardiner argues, as we do in the first part of this introduction, that some kind of reckoning needs be made around the historical question of Scottish scientific and 
intellectual legacies-now also culpabilities-enabling the technological, philosophical and socio-political shifts to the kind of petroculture that has contributed significantly to the existential problems that the world now faces. This historical framing is gaining prominence in the global academy and elsewhere. Such a reckoning would work in tandem with any general acknowledgment of the notable efforts and means to mitigate and confront them in Scottish environmental culture. Gardiner attempts this in his recuperative positing of a cluster of writing, most notably poetry, that emerged from the anti-nuclear resistance of the 1980s. This offers a means to rethink the terms and conditions of nature and the natural, terms and concepts that Gardiner theorises as determined and governed by a historical and contemporary British culture and polity uninvested in the requisite forms of ethics and politics required for radical environmental transformation.

Gary Mackenzie's "Ecopoetic Translation" of Duncan Bàn Maclntyre long 18th century Gaelic poem Moladh Beinn Dóbhrain (In Praise of Ben Dorain) provides an example of how texts from Scottish literary history can be approached with an ecocritical methodology informed by contemporary scholarship. Such re-readings extend to the prolific unconscious ecological signatures and range of environmental acts impressed in and across the diverse range of Scottish literary work. Here, Mackenzie engages with translation as "an underexplored area of ecocriticism, despite increasing interest in the negotiation of human and non-human sign systems suggested by biosemiotics" to produce a version of the original poem that "is not simply a translation, but incorporates Moladh Beinn Dóbhrain into a new, longer work." An expansion of our ecological sensibilities can certainly come from what Mackenzie calls "intense noticing" when it comes to observing surrounding nature and apprehending natural movement and time in granular form.

As Arianna Introna demonstrates in her article on "Social Reproduction at the End of Times: Jenni Fagan's and John Burnside's Degrowth Imaginaries", discussing Fagan's The Sunlight Pilgrims and Burnside's estranging and enigmatic 2017 post-collapse novel Havergey, a restoration or transition of "sustainable" community does not necessarily entail a return to some ideal or golden age notion of sustainability. Nor does it imagine a world of green capitalism close to the condition of the present. It is something else altogether, as alluring as it is disquieting, and the unsettling, subjunctive narrative form of Burnside's novel (again, like his other, more evidently dystopian novel Glister) promotes this sense of radical difference. As Introna argues, with reference to the arguments of the degrowth movement and the work of Silvia Federici, unless capitalist social relations are radically transformed, the chances of actual sustainable futures are minimal.

Michael Paye's article "Regulating Desire: The Nature of Exhaustion in Ali Smith's Hotel World and Ewan Morrison's Tales from the Mall", reads these two novels worldecologically. He demonstrates that work that is not overtly or representatively "environmental" in emphasis, context and topic can in fact be constitutively just that, riffing from the work of theorists of late capitalism such as Nancy Fraser and particularly Jason Moore's elaboration of capitalism's long durée externalisation and appropriation of "cheap nature." Paye identifies themes and forms of development, exhaustion, disjunctive temporality, suburbanisation and unseen acts of exploitation and commodification in Smith's and Morrison's work. This he elicits as part of a longer heteronormative regime of ecological exhaustion that extends across multiple sectors within and outwith Scotland.

Frederick Buell (2012) has identified the repeated cultural motifs of oil's historical expression as entanglements of "exuberance and catastrophe", with associative forms of dread intensifying as the oil era advanced. We can identify these in Scottish petroculture, as Alexandra Campbell notes in her article on "Extractive Poetics: Marine Energies in Scottish Literature." Campbell demonstrates how recent visual and poetic registrations of marine renewables in Scottish culture and literature afford means to reconceive Scottish seascapes as techno-cultural spaces producing "a different mode of ecological relation with marine environments" (p. 2) than the extractivist and enclosing infrastructures of petrocapitalism and carbon accumulation she reads in a range of counterexamples. 
Some significant aspects remain relatively unstudied within Scottish studies, as Timothy Baker argues in his illuminating article "Perpetual Vanishing: Animal Lives in Contemporary Scottish Fiction". Baker focuses on the absence of the animal and animality, a "spectral or peripheral" figure in contemporary Scottish literary studies. He takes the development of a subfield such as animal studies to provide the means to realise such an observation. This signals wider issues with the anthropocentric nature of literary genres, most notably the novel, but also with the lack of multispecies awareness in aspects of Scottish literary criticism. "Looking at nonhuman animals" (p. 11) Baker states, "allows for new ideas of nature and the wild, and a different approach to the questions of land that have long dominated Scottish writing."

Author Contributions: This article represents a joint and equal contribution by G.M. and C.S. All authors have read and agreed to the published version of the manuscript.

Funding: Graeme Macdonald's work here was partly funded by the Swedish Research Council FORMAS funded project Climaginaries: Narrating Socio-Cultural Transitions to a Post-Fossil Society. The funders had no role in the design of the study; in the collection, analyses, or interpretation of data; in the writing of the manuscript, or in the decision to publish the results.

Acknowledgments: The authors extend thanks to the peer reviewers who gave their time and expertise over the duration of this project. We would also like to thank the editorial team at Humanities.

Conflicts of Interest: The authors declare no conflict of interest.

\section{References}

Albritton-Johnson, Fredrik. 2013. Enlightenment's Frontier: The Scottish Highlands and the Origins of Environmentalism. New Haven: Yale. Anderson, Benedict. 2006. Imagined Communities: Reflections on the Origin and Spread of Nationalism (Revised and Extended. ed.). London: Verso.

Anderson, Kevin. 2020. What Does the Paris Agreement Mean for Scotland? Scotland's Climate Assembly. December 13. Available online: https:/ /www.climateassembly.scot/node/129/ (accessed on 17 December 2020).

Barret, Ross, and Daniel Worden, eds. 2014. Oil Culture. Minneapolis: Minnesota UP.

Billig, Michael. 2010. Banal Nationalism. London: Sage.

Bomberg, Elizabeth, and Nicola McEwen. 2014. Sub-state Climate Pioneers: The Case of Scotland. Regional and Federal Studies 24: 63-85.

Bonneuil, Christophe, and Jean-Baptiste Fressoz. 2016. The Shock of the Anthropocene: The Earth, History and Us. London: Verso.

Buell, Frederick. 2012. A Short History of Oil Culture: Or, the Marriage of Catastrophe and Exuberance. Journal of American Studies 46: 273-93. [CrossRef]

Clark, Timothy. 2015. Ecocriticism on the Edge. The Anthropocene as a Threshold Concept. London: Bloomsbury.

Crutzen, Paul, and Eugene Stoermer. 2000. The "Anthropocene". Global Change Newsletter 41: 17-18.

Daggett, Cara. 2019. The Birth of Energy: Fossil Fuels, Thermodynamics and the Politics of Work. Durham: Duke University Press.

Debarbieux, Bernard, and Carlo Salzani. 2011. The Political Meaning of Landscape (Through the Lens of Hannah Arendt's The Human Condition). In The Place of Landscape. Concepts, Contexts, Studies. Edited by Jeff Malpas. Cambridge: MIT Press, pp. 132-45.

Gairn, Louisa. 2008. Ecology and Modern Scottish Literature. Edinburgh: EUP.

Heise, Ursula. 2008. Sense of Place and Sense of Planet: The Environmental Imagination of the Global. Oxford: OUP.

Hickel, Jason. 2020. Quantifying National Responsibility for Climate Breakdown: An equality-based attribution approach for carbon dioxide emissions in excess of the planetary boundary. The Lancet: Planetary Heath 4: 399-404. [CrossRef]

Jamie, Kathleen. 2005. Findings. London: Sort of Books.

Jessop, Ralph. 2012. Coinage of the Term Environment: A Word without Authority and Carlyle's Displacement of the Mechanical Metaphor. Literature Compass 9: 708-20. [CrossRef]

Klein, Naomi. 2019. On Fire: The Burning Case for a Green New Deal. London: Allen Lane.

LeMenager, Stefanie. 2014. Living Oil: Petroleum Culture in the American Century. Oxford: OUP.

Lieven, Anatol. 2020. Climate Change and the Nation State: The Realist Case. London: Allen Lane.

Lilley, Deborah. 2013. Kathleen Jamie: Rethinking the externality and idealisation of nature. Green Letters 17: 16-26. [CrossRef]

Little, Gavin. 2016. Energy and the Scotland Act 2016. Edinburgh Law Review 20: 394-99. [CrossRef]

Malm, Andreas. 2016. Fossil Capital: The Rise of Steam Power and the Roots of Global Warming. London: Verso.

Moore, Jason W., ed. 2016. Anthropocene or Capitalocene? Nature, History, and the Crisis of Capitalism. Oakland: PM Press.

Puig de la Bellacasa, Maria. 2017. Matters of Care: Speculative Ethics in More Than Human Worlds. Minneapolis: University of Minnesota Press.

Silver, Christopher. 2018-2019. A Just Transition: From Fossil Fuels to Environmental Justice. DesmogUK, October 2018-May 2019. 5 parts. Available online: https:/ / www.desmog.co.uk/just-transition-fossil-fuels-environmental-justice (accessed on 17 December 2020). 
Scottish Government. 2017. Scotland and California Tackling Climate Change. April 3. Available online: https://www.gov.scot/news / scotland-and-california-tackling-climate-change/ (accessed on 9 February 2021).

Silver, Christopher. 2020. Scotland's Fossil Fuel Sector Hangs in the Balance as Ministers Consider Calls to Intervene. DesmogUK, May 15. Available online: https://www.desmog.co.uk/2020/05/15/scotland-s-fossil-fuel-sector-hangs-balance-ministersconsider-calls-intervene (accessed on 17 December 2020).

Smout, T. C. 2000. Nature Contested: Environmental History in Scotland and Northern England Since 1600. Edinburgh: EUP.

Studholme, Maggie. 2007. Patrick Geddes: Founder of Environmental Sociology. The Sociological Review 55: 441-59. [CrossRef]

Szeman, Imre. 2019. On Petrocultures: Globalization, Culture and Energy. Morgantown: WVU Press.

Trexler, Adam. 2015. Anthropocene Fictions: The Novel in a Time of Climate Change. Charlottesville: University of Virginia Press.

Wallerstein, Immanuel. 2006. The Curve of American Power. New Left Review 40: 77-94.

Walter, François. 2004. Les Figures Paysagères de la Nation: Territoire et Paysage en Europe (16e-20e siècle). Paris: Éd. de l'École des Hautes Études en Sciences Sociales.

Watts, Laura. 2019. Energy at the End of the World. An Orkney Islands Saga. Cambridge: MIT Press.

Whitehead, Mark, Rhys Jones, and Martin Jones. 2007. The Nature of the State: Excavating the Political Ecologies of the Modern State. Oxford: Oxford University Press.

Wilson, Sheena, Adam Carlson, and Imre Szeman, eds. 2017. Petrocultures: Oil, Politics, Culture. Montreal: McGill-Queens University Press. 